\title{
Interaction between a Liquid Surface and an Impinging Gas Jet
}

\author{
Miguel A. Barron, Dulce Y. Medina, Joan Reyes \\ Departamento de Materiales, Universidad Autonoma Metropolitana Azcapotzalco, Mexico City, Mexico \\ Email: bmma@correo.azc.uam.mx
}

How to cite this paper: Barron, M.A., Medina, D.Y. and Reyes, J. (2021) Interaction between a Liquid Surface and an Impinging Gas Jet. World Journal of Engineering and Technology, 9, 793-803. https://doi.org/10.4236/wjet.2021.94055

Received: September 18, 2021

Accepted: November 7, 2021

Published: November 10, 2021

Copyright (c) 2021 by author(s) and Scientific Research Publishing Inc. This work is licensed under the Creative Commons Attribution International License (CC BY 4.0).

http://creativecommons.org/licenses/by/4.0/

\section{(c) (i) Open Access}

\begin{abstract}
The water-air and Wood's metal-air systems are modeled by means of Computational Fluid Dynamics to study the interaction between a liquid surface and an impinging air jet under the near field blowing conditions. The effect of the air jet velocity, the height of the injection lance, and the density of the liquid on the depth of the formed cavity is numerically studied. The CFD results of the cavity depth are compared with results previously reported by other authors. The emergence of the splashing phenomenon is predicted in terms of the critical velocity for each liquid-air system. Besides, the blowing number indicates that the drop generation rate is not significant for jet velocities below the critical velocity, and therefore neither the splashing is significant.
\end{abstract}

\section{Keywords}

Cavity Depth, CFD, Impinging Gas Jet, Lance Height, Liquid-Gas Interaction, Splashing

\section{Introduction}

Impinging of gas jets in liquid surfaces is employed for different purposes in several industries, e.g. metallurgical, gas cleaning, mixing, and so on. Interaction between a liquid surface and an impinging gas jet has been studied for a long time. Different approaches have been used to study this problem: analytical [1], numerical [2], and experimental [3].

During the interaction between a liquid surface and an impinging gas jet, three main stages are present. These are dimpling, splashing, and penetration [2] [4] [5]. Dimpling is the formation of a shallow depression in the liquid surface at low velocity of the gas jet or at high lance injection height. During splashing, due to momentum transfer, shear stresses exceed surface tension and gravitational 
forces, and as a consequence drops are ejected from the liquid surface. The splashing phenomenon arises when the jet velocity is increased beyond a critical value, which depends on the geometric configuration of the system and the physical properties of the involved phases. The above phenomenon has been previously numerically analyzed by some of the authors of the present work [6] [7]. In the penetration stage, the depth of the cavity is significantly increased. The cavity depth is directly proportional to the jet velocity and inversely proportional to the liquid density and the height of the injection lance.

In the vast majority of published works, it is considered that the ratio between the height of the injection lance above the liquid surface $(\mathrm{H})$ and the diameter of such lance (D), as is depicted in Figure 1, is greater than 10, i.e. H/D > 10. There are few studies reported for H/D $<10$. Among the latter is a recent work [8], in which the water-air and the Wood's metal-air systems interactions are experimentally and numerically simulated for $\mathrm{H} / \mathrm{D}$ values of $0.8,1.7$ and 3 .

Here, experimental work reported in [8] is simulated by means of Computational Fluid Dynamics (CFD) to investigate the effect of the velocity of the air jet, the height of the injection lance, and the density of the liquid on the depth of the formed cavity. The results on the cavity depth are compared with results of other authors. In addition, the emergence of the splashing phenomenon is predicted in terms of the critical velocity of each system. The oscillation of the liquid surface is not considered here since the turbulence model used generates only average

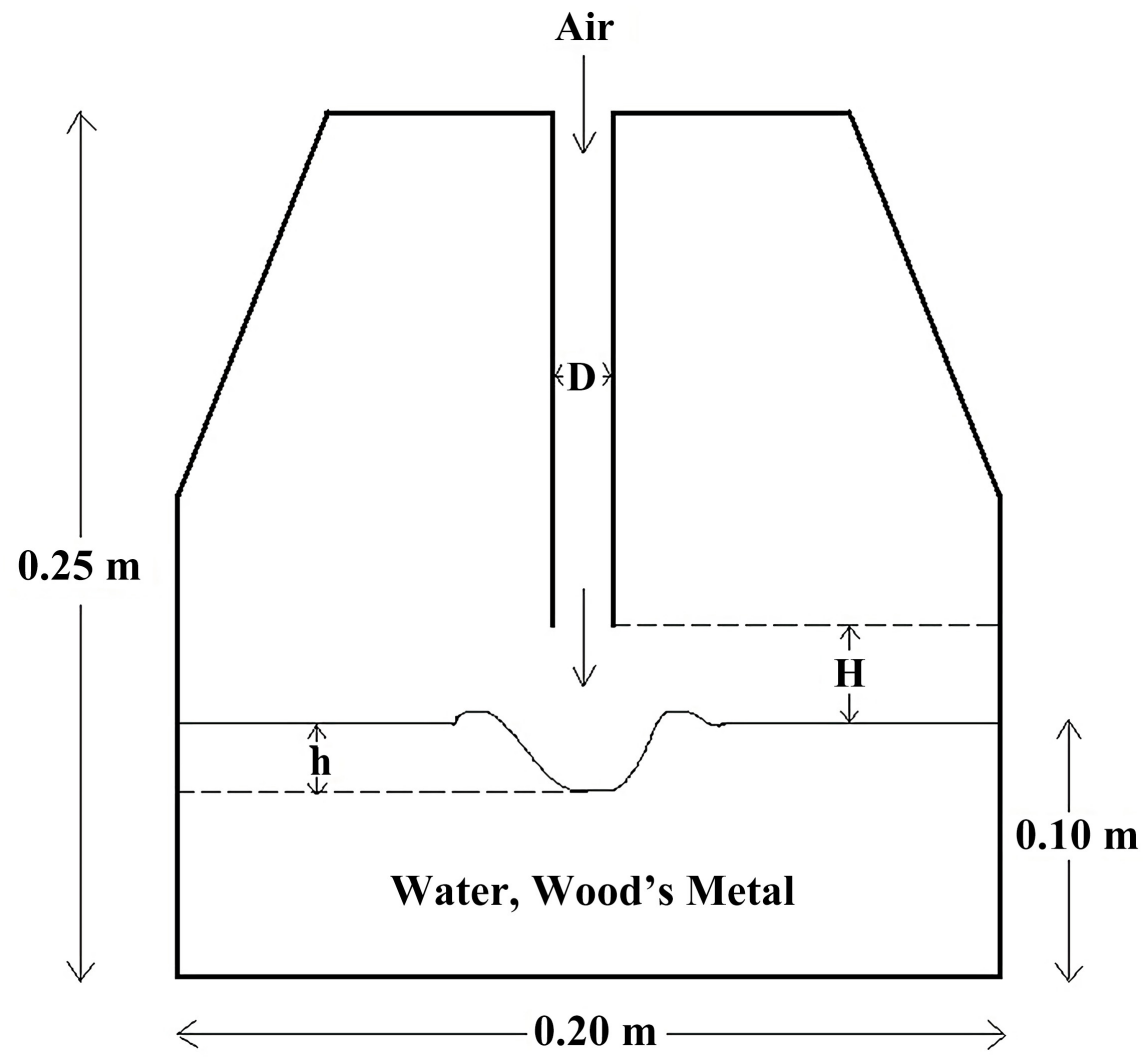

Figure 1. The liquid-air systems considered [8]. 
values of the variables involved. The system that is simulated in this work, and that is the same one used in [8], is shown in Figure 1.

\section{Mathematical Model and Computer Simulations}

Computational Fluid Dynamics (CFD) is employed to study the interaction between a liquid surface and an impinging air jet. The air jet is vertically impinged onto a liquid (water or Wood's metal) surface through a nozzle located at the top of the liquid surface. The process is considered isothermal. The equations of continuity and momentum, the K- $\varepsilon$ model for turbulence and the Volume of Fluid model for multiphase flow are employed in 2D CFD transient numerical simulations. Meshing of the 2D geometrical model yielded 69,824 trilateral cells.

A blowing number $\left(N_{B}\right)$ is defined as follows in [9] [10] [11]:

$$
N_{B}=\frac{\rho_{g}\left(\eta u_{j}\right)^{2}}{2 \sqrt{\sigma_{l} g \rho_{l}}}
$$

where $u_{j}$ is the jet velocity, $\rho_{g}$ is the air density, $\rho_{l}$ is the liquid density, $g$ is the acceleration of gravity, and $\sigma$ is the liquid surface tension. A constant $\eta=$ 0.44721 is introduced [9] [12]. Based on the Kelvin-Helmholtz instability criterion, in [9] it is reported that for the onset of splashing the blowing condition must satisfy that $N_{B}>1$. In addition, a critical velocity $u_{c r}$ for the onset of splashing is defined as follows in [8]:

$$
u_{c r}=\left\{\frac{48 g \sigma_{l}\left(\rho_{l}-\rho_{g}\right)}{\rho_{g}^{2}}\right\}^{0.25}
$$

\section{Results for Water}

\subsection{Splashing}

In the CFD simulations, the physical properties of the fluids involved are shown in Table 1.

For the air-water system, and using the above values of the physical properties, Equation (2) yields a critical velocity for splashing $u_{c r}=12.53 \mathrm{~m} / \mathrm{s}$. As in [8], three jet velocities $\left(u_{j}\right)$ were employed in the CFD numerical simulations, namely $9.46,18.5$, and $27.4 \mathrm{~m} / \mathrm{s}$. Nozzle diameter value $\mathrm{D}$ was set to $0.01 \mathrm{~m}$. Table 2 shows that for jet velocities of 18.5 and $27.4 \mathrm{~m} / \mathrm{s}$ the two aforementioned conditions for

Table 1. Physical properties of the considered fluids [8].

\begin{tabular}{ccccc}
\hline Fluid & Temperature, ${ }^{\circ} \mathrm{C}$ & Density, $\mathrm{kg} / \mathrm{m}^{3}$ & Viscosity, $\mathrm{kg} /(\mathrm{m} \cdot \mathrm{s})$ & $\begin{array}{c}\text { Surface tension, } \\
\mathrm{N} / \mathrm{m}\end{array}$ \\
\hline Air & 27 & 1.17 & $1.79 \times 10^{-5}$ & --- \\
Water & 27 & 997 & $8.51 \times 10^{-4}$ & 0.072 \\
Wood's Metal & 105 & 9560 & $3.26 \times 10^{-3}$ & 0.431 \\
\hline
\end{tabular}


Table 2. Blowing number, drop generation rate, and splashing conditions for the considered jet velocities.

\begin{tabular}{cccc}
\hline Jet velocity, $\mathrm{m} / \mathrm{s}$ & $N_{B}$ & $G_{d} \mathrm{~kg} / \mathrm{s}$ & Splashing? \\
\hline 9.46 & 0.3946 & $2.006 \times 10^{-6}$ & No \\
18.5 & 1.5089 & $2.8246 \times 10^{-4}$ & Yes \\
27.4 & 3.3100 & $5.1676 \times 10^{-3}$ & Yes \\
\hline
\end{tabular}

splashing are satisfied, i.e. $N_{B}>1$ and $u_{j}>u_{c r}$ In Table 2, it is also shown the drop generation rate $G_{d}$ in $\mathrm{kg} / \mathrm{s}$, which is determined from the expression [9]:

$$
G_{d}=\frac{Q_{g} N_{B}^{3.2}}{\left[2.6 \times 10^{6}+2.0 \times 10^{-4} N_{B}^{12}\right]^{0.2}}
$$

where $Q_{g}$ is the air volumetric flow rate, $\mathrm{m}^{3} / \mathrm{s}$. In the above equation, $Q_{g}$ is calculated from

$$
Q_{g}=\left(\frac{\pi D^{2}}{4}\right) u_{j}
$$

Table 2 shows that for $u_{j}=9.46 \mathrm{~m} / \mathrm{s}$ the drop generation rate is not significant, and therefore neither the splashing is significant.

\subsection{Cavity Depth}

The cavity depth $h$, as is depicted in Figure 1, was determined from the results of the CFD simulations, and compared with the experimental results of [8]. Besides, $h$ was estimated from the expressions proposed in [3] and [12]. In [3] $h$ is estimated from a modified Froude number $F r_{m}$ :

$$
h=4.1 D\left(F r_{m}\right)^{1 / 3}
$$

In the above equation, $F r_{m}$ is defined as

$$
F r_{m}=\frac{(4 / \pi)^{2} \rho_{g} u_{i}^{2}}{\rho_{l} g D}
$$

where $u_{i}$ is the impact velocity of the air jet. The impact velocities of the jets were obtained by scanning the vertical components of the jet velocity in the vicinity of the liquid-gas interface, as is depicted in Figure 2. Due to jet decaying, the impact velocity is less than the nominal jet velocity.

In [12] an implicit expression for describing the cavity depth is proposed:

$$
\frac{M \cos \theta}{\rho_{l} g n H^{3}}=\frac{\pi h}{2 K^{2} \eta H}\left[\left(1+\frac{h}{H}\right)^{2}+\frac{4 \beta_{*} \sigma_{l}}{\rho_{l} g H^{2}}\right]
$$

where $M$ is the momentum flow rate of the air jet, $\theta$ is the lance inclination angle, $n$ is the number of nozzles, $K=11.5$ is a constant, $\eta$ is a constant which depends on the lance height $H$ (see Figure 1 ), and $\beta_{*}=125$ is a constant too. $M$ is determined from the expression: 


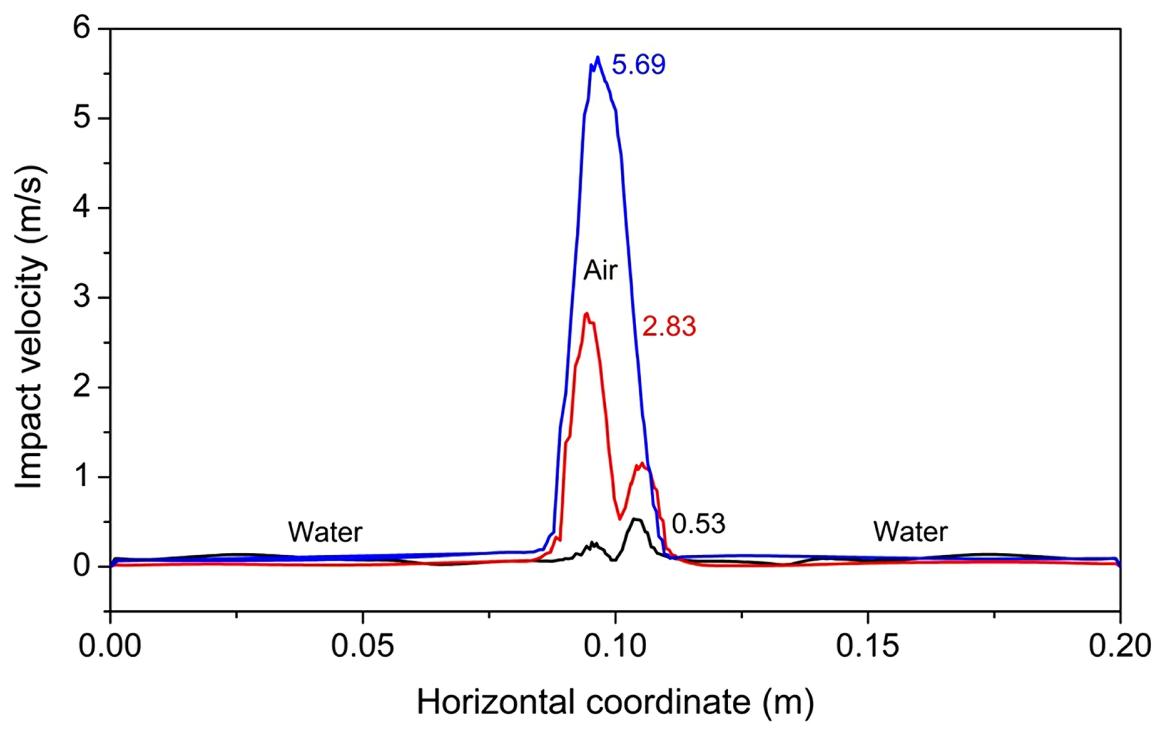

Figure 2. Impact velocity of the air jets for $H=0.008 \mathrm{~m}$. Jet velocity: Black $=9.46 \mathrm{~m} / \mathrm{s}$, red $=18.5 \mathrm{~m} / \mathrm{s}$, blue $=27.4 \mathrm{~m} / \mathrm{s}$.

$$
M=\left(\frac{\pi}{4}\right) \rho_{g} D^{2} u_{j}^{2}
$$

For its part $\eta$ depends on $H$ in an empirical way as follows [12]:

$$
\eta=a H^{2}+b H+c
$$

where $a=15.84127, b=-2.57058$, and $c=0.48989$. Besides, in Equation (7) $\theta=$ 0 and $n=1$ for the liquid-air system of Figure 1 considered here.

A comparison is made for the cavity depth among the CFD results of this work and the experimental results of [8] and the analytical results of [3] [12]. This comparison is observed in Table 3, and is graphically depicted in Figure 3. It is observed that as the jet velocity is increased, a small underestimation (less than $0.005 \mathrm{~m}$ ) of the results of [3] and this work arises related to the experimental results of [8]. Inversely, an overestimation of around $0.005 \mathrm{~m}$ is present between the depth cavity results of [12] and the experimental results of [8].

The dependence of the cavity depth on the lance height and the jet velocity was numerically explored. Results are depicted in Figure 4. Presumably, cavity depth is promoted by high momentum transfer, consequently cavity depth is increased as the jet velocity is increased or the height of the injection lance is decreased. This is corroborated in Figure 4.

\subsection{Water Surface-Air Jet Interaction}

During the interaction between a liquid surface and an impinging gas jet three main successive stages arise. These stages are dimpling, splashing, and penetration [2] [4] [5]. Dimpling is the formation of a shallow depression in the liquid surface at a low velocity of the gas jet or at a high height of the injection lance (see Figure 1). As the jet velocity is increased and it exceeds a certain critical value given by Equation (2), the splashing phenomenon arises. During 
Table 3. Comparison of the cavity depth among the CFD results of this work and those reported by other researchers, for $H=0.008$.

\begin{tabular}{ccccc}
\hline Jet velocity, m/s & $h, \mathrm{~m}[8]$ & $h, \mathrm{~m}[3]$ & $h, \mathrm{~m}[12]$ & $h, \mathrm{~m}(\mathrm{CFD})$ \\
\hline 9.46 & 0.008 & 0.007 & 0.008 & 0.008 \\
18.5 & 0.025 & 0.022 & 0.026 & 0.020 \\
27.4 & 0.040 & 0.035 & 0.044 & 0.036 \\
\hline
\end{tabular}

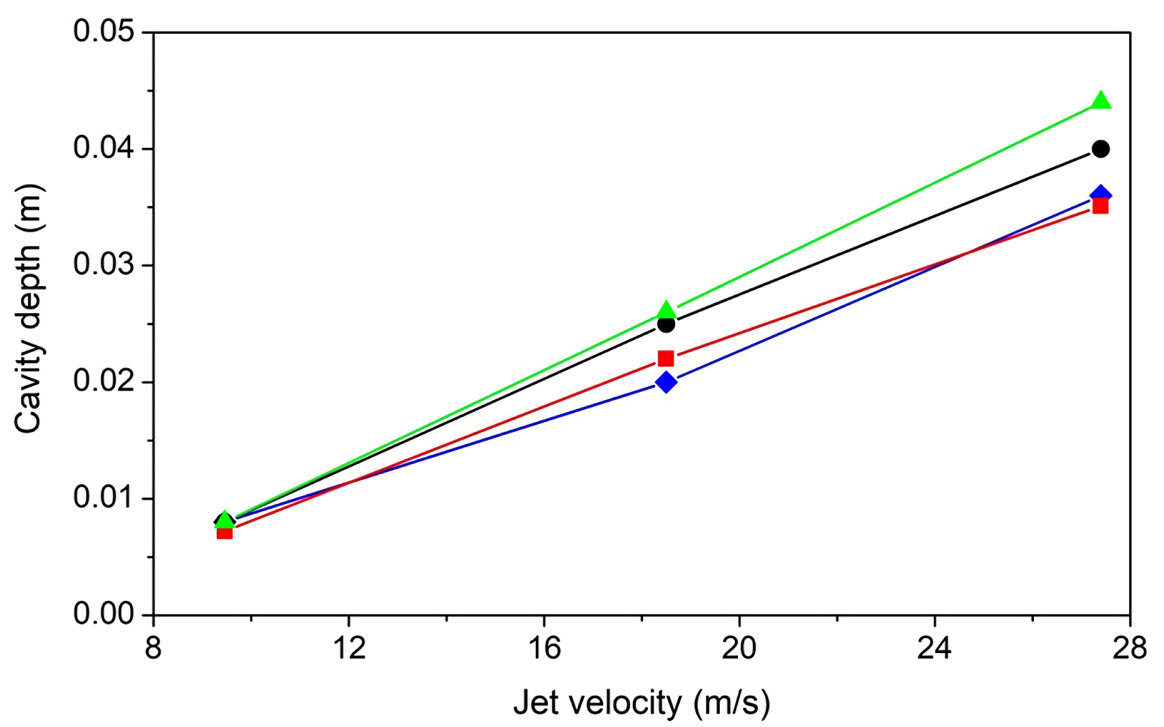

Figure 3. Comparison of the cavity depth among the CFD results of this work and those reported by other researchers, for $H=0.008$. Experimental [8] = black, based on Froude number [3] = red, based on jet momentum [12] = green, CFD (this work) $=$ blue.

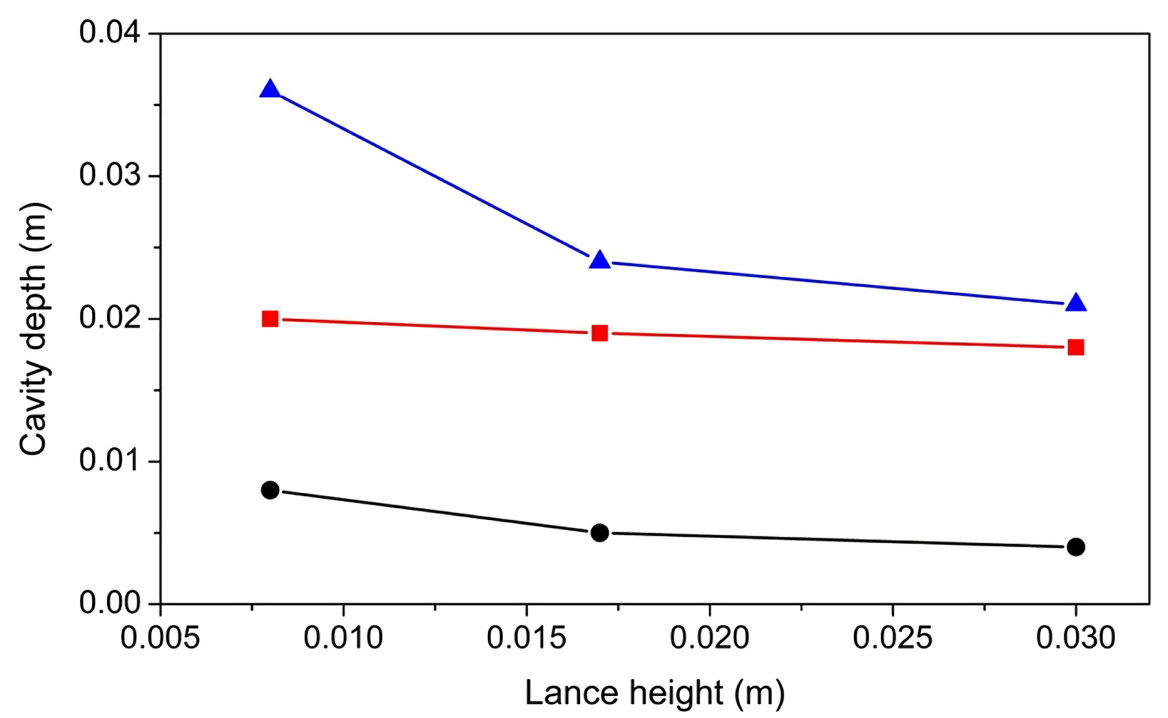

Figure 4. Cavity depth as function of lance height. Jet velocity: Black $=9.46 \mathrm{~m} / \mathrm{s}$, red $=$ $18.5 \mathrm{~m} / \mathrm{s}$, blue $=27.4 \mathrm{~m} / \mathrm{s}$.

splashing small liquid drops are ejected from the liquid surface due to that shear stresses in the liquid surpass gravitational and surface tension forces. In the pe- 
netration stage the cavity depth is directly proportional to the jet velocity and inversely proportional to the lance height.

In order to study the interaction between the water surface and the impinging air jet, several CFD transient 2D numerical simulations were carried out. As in [8], three values of the jet velocity were considered, namely 9.46, 18.5 and 27.4 $\mathrm{m} / \mathrm{s}$, respectively. Besides, three values of the lance height were assumed: 0.008 , 0.017 and $0.03 \mathrm{~m}$. In accordance to Table 2, no splashing was expected for a jet velocity of $9.46 \mathrm{~m} / \mathrm{s}$. This is appreciated in Figure 5, in which just a small depression is formed and no splashing is detected.

A sequential dynamic behavior consisting in dimpling, splashing and penetration stages during water surface-air jet interaction is predicted if jet velocity becomes beyond the critical value of $12.53 \mathrm{~m} / \mathrm{s}$, as was explained in Section 3.1. Figure 6

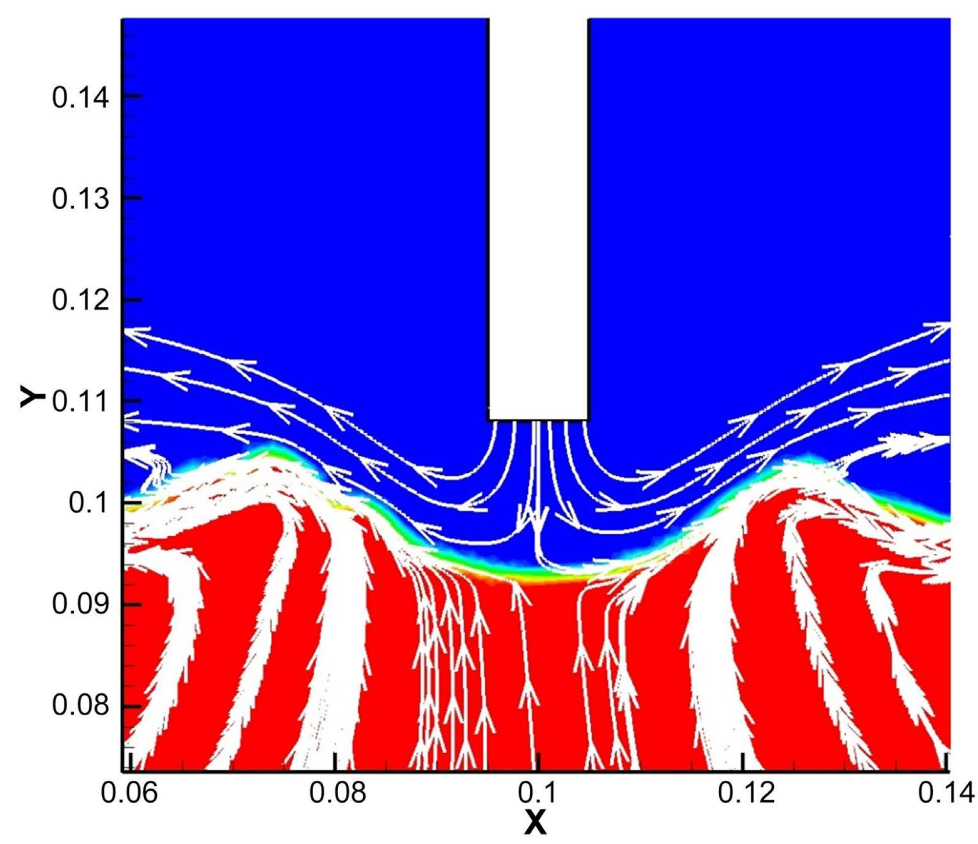

Figure 5. Phases distribution and streamtraces for a jet velocity of $9.46 \mathrm{~m} / \mathrm{s}$ and a lance height of $0.008 \mathrm{~m}$. Red phase is water, blue phase is air.
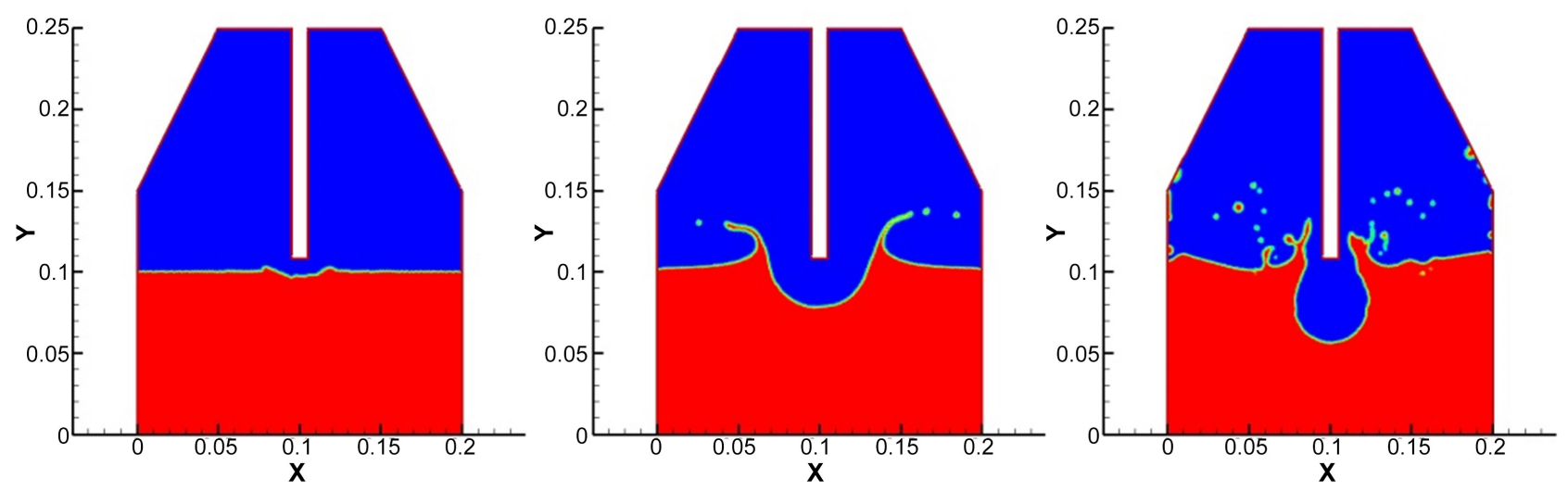

Figure 6. Dimpling, splashing and penetration stages. Jet velocity $=27.4 \mathrm{~m} / \mathrm{s}$, lance height $=0.008 \mathrm{~m}$. Time from the start of blowing: Left $=0.02 \mathrm{~s}$, center $=0.1 \mathrm{~s}$, right $=0.4 \mathrm{~s}$. Red phase is water, blue phase is air. 
depicts the above behavior for a jet velocity of $27.4 \mathrm{~m} / \mathrm{s}$ and a lance height of $0.008 \mathrm{~m}$.

Figure 7 summarizes the water surface-air jet interaction for the values of the jet velocity $u_{j}(9.46,18.5,27.4 \mathrm{~m} / \mathrm{s})$, and the values of the lance height $H(0.008$, $0.017,0.03 \mathrm{~m}$ ) considered in the CFD runs. The critical velocity $u_{c r}$ for the water-air system is $12.53 \mathrm{~m} / \mathrm{s}$, which was determined from Equation (2), and it becomes
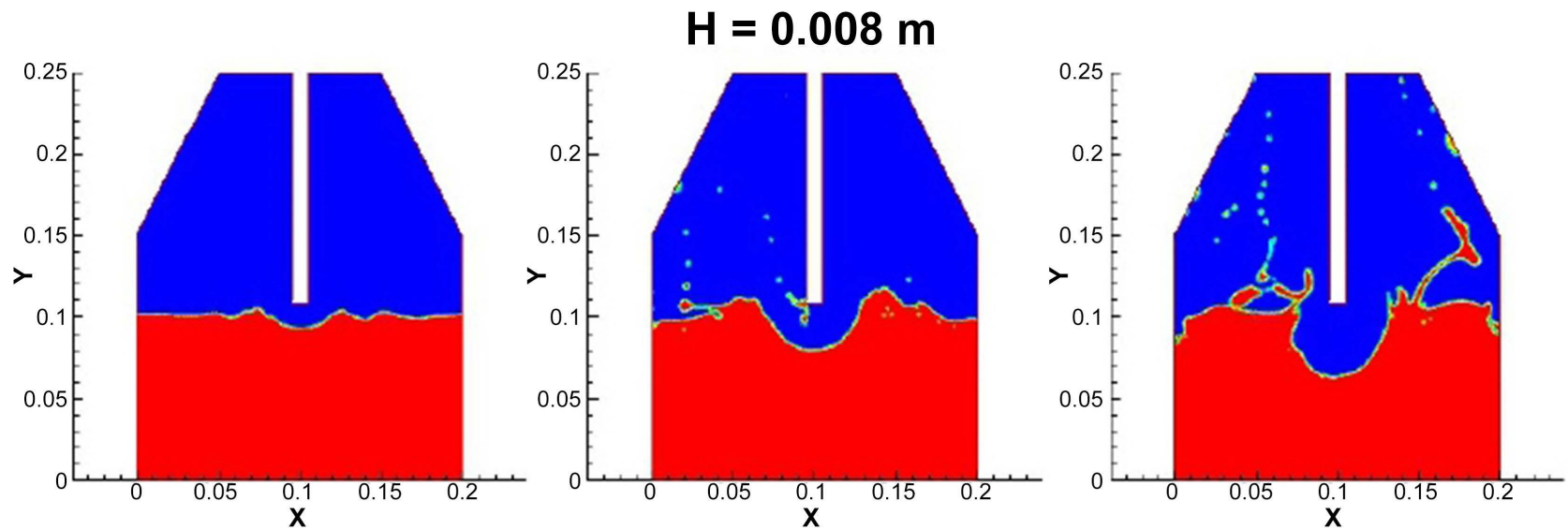

\section{$\mathrm{H}=\mathbf{0 . 0 1 7} \mathrm{m}$}
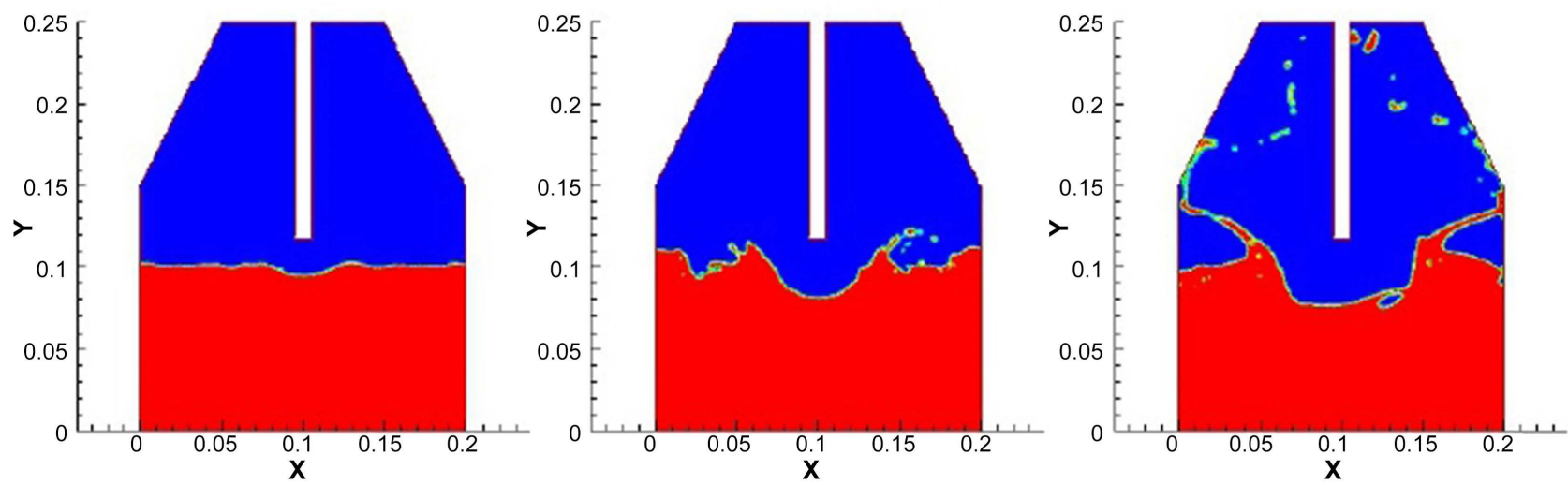

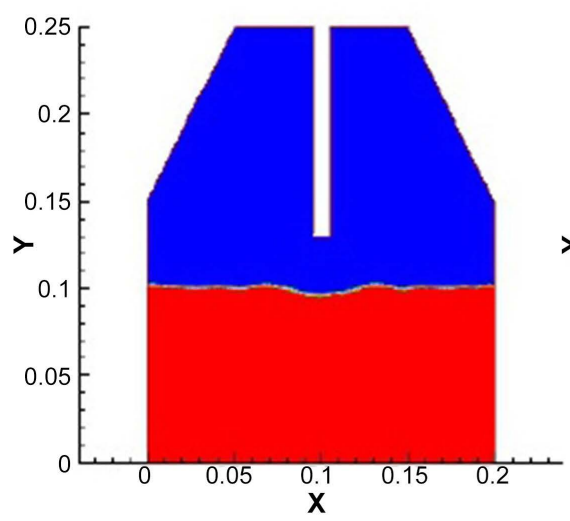

$9.46 \mathrm{~m} / \mathrm{s}$

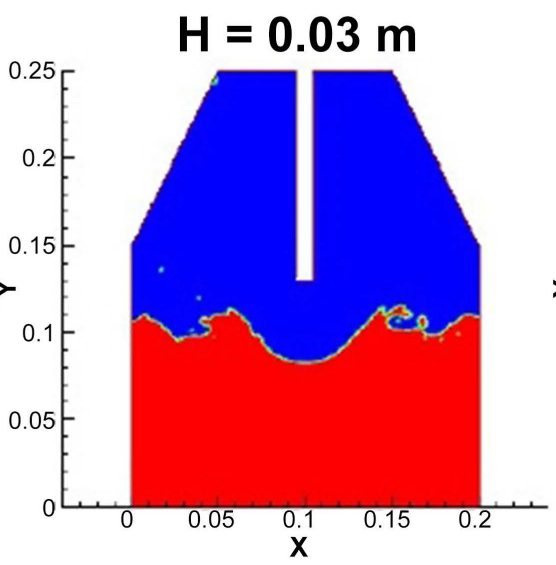

$18.5 \mathrm{~m} / \mathrm{s}$

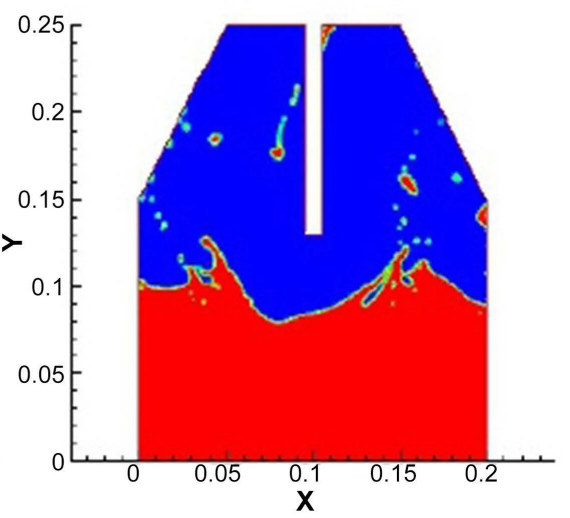

$27.4 \mathrm{~m} / \mathrm{s}$

Figure 7. Water surface-air jet interaction for several values of jet velocity and lance height. First column: $u_{j}=9.46 \mathrm{~m} / \mathrm{s}$, second column: $u_{j}=18.5 \mathrm{~m} / \mathrm{s}$, third column: $u_{j}=27.4 \mathrm{~m} / \mathrm{s}$. First row: $H=0.008 \mathrm{~m}$, second row: $H=0.017 \mathrm{~m}$, third row: $H=0.03 \mathrm{~m}$. Red phase is water, blue phase is air. 
the key to explain that interaction. The first column corresponds to $u_{j}=9.46$ $\mathrm{m} / \mathrm{s}$, for which $u_{j}<u_{c r}$ The cavity depth decreases as the lance height is increased, however no splashing is observed, as predicted. In the second and the third columns, corresponding to $u_{j}=18.5$ and $27.4 \mathrm{~m} / \mathrm{s}$, respectively, splashing and penetration occur given that in both cases the conditions $N_{B}>1$ and $u_{j}>u_{c r}$ are met regardless the lance height. However, due to the higher moment more intense splashing and more penetration depth are present for $u_{j}=27.4 \mathrm{~m} / \mathrm{s}$. Besides, the height reached by the water drops ejected from the water surface is greater for $u_{j}=27.4 \mathrm{~m} / \mathrm{s}$ than for $u_{j}=18.5 \mathrm{~m} / \mathrm{s}$.

\section{Results for Wood's Metal}

CFD numerical simulations were also carried using Wood's metal instead of water. The physical properties of the Wood's metal are shown in Table 1. Using these properties in Equation (2) yields $u_{c r}=34.50 \mathrm{~m} / \mathrm{s}$ for this liquid.
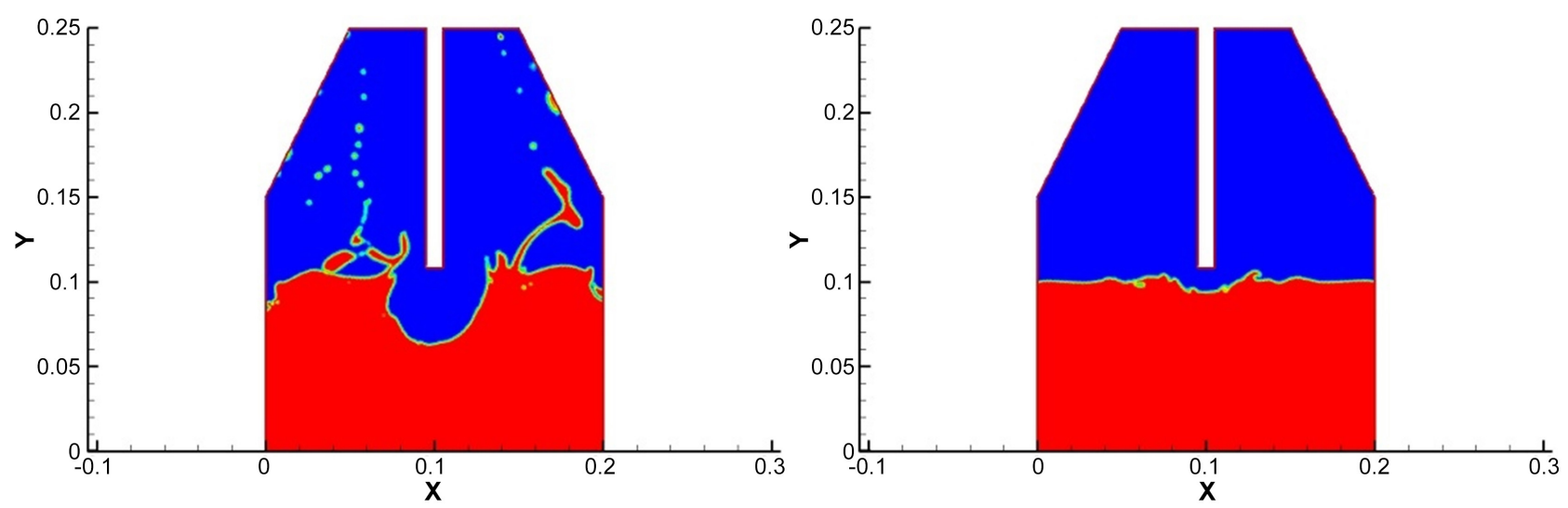

Figure 8. Phases distribution for $u_{j}=27.4 \mathrm{~m} / \mathrm{s}$ and $H=0.008$. Left $=$ water, right $=$ Wood's metal. Time $=0.6 \mathrm{~s}$. Blue phase is air, red phase is the corresponding liquid.

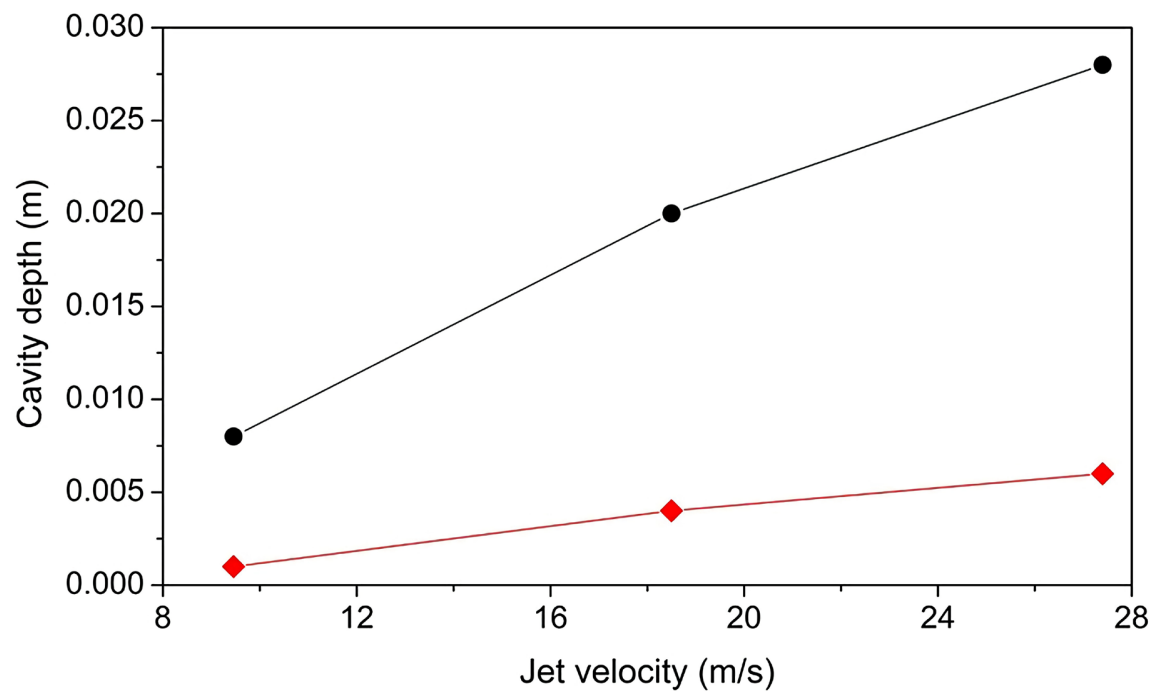

Figure 9. Cavity depth as function of the jet velocity for Wood's Metal and water considering a lance height of $0.008 \mathrm{~m}$. Black = water, red = Wood's metal. 
Figure 8 shows a comparison of the interactions between the water-air system (left) and the Wood's metal-air system (right) using the same jet velocity, 27.4 $\mathrm{m} / \mathrm{s}$, and the same lance height, $0.008 \mathrm{~m}$, in the computer runs. For water, intense splashing is expected, as is observed in the left side of Figure 8. For the Wood's metal no splashing is expected whatever the value of the jet velocity given that at no time it is verified that $u_{j}>u_{c r}$

Figure 9 shows the cavity depth as function of the jet velocity for Wood's Metal and water considering a lance height of $0.008 \mathrm{~m}$. Since the density of the Wood's metal is much higher than that of the water, the cavity height is expected to be much lower for the first one than for the second one regardless of the height of the lance used. This is because the gravitational forces exerted on Wood's metal are greater than those exerted on water. The surface tension, in accordance to [8], is not relevant to determine the cavity depth.

\section{Conclusions}

The system proposed by Sato et al. [8] was analyzed by means of CFD simulations to study the interaction between a liquid surface and an impinging air jet under the near field blowing conditions. The effect of the air jet velocity, the height of the injection lance, and the density of the liquid in the cavity depth was analyzed using water and Wood's metal as liquids. In addition, the emergence of the splashing phenomenon was predicted in terms of critical velocity.

From the results of the numerical simulations the following conclusions arise:

1) The three stages (dimpling, splashing, penetration) experimentally and numerically reported in the literature during the interaction of a liquid surface with an impinging gas jet are adequately reproduced by the CFD simulations.

2) The critical velocity of the water-air system provides a useful criterion to predict the splashing phenomenon. For jet velocity below $12.53 \mathrm{~m} / \mathrm{s}$ no splashing arises.

3) The blowing number provides correct information, at least qualitatively, on the drop generation rate.

4) The variables studied here (jet velocity, injection lance height, liquid density) significantly affect the depth of the cavity.

5) The depth of the cavity is directly proportional to the speed of the jet and inversely proportional to the height of the lance and the density of the liquid.

6) Under the operating conditions simulated here, a very high density of the liquid can inhibit the splashing phenomenon.

\section{Conflicts of Interest}

The authors declare no conflicts of interest regarding the publication of this paper.

\section{References}

[1] Rossler, R.S. and Stewart, G.H. (1968) Impingement of Gas Jets on Liquid Surfaces. 
Journal of Fluid Mechanics, 31, 163-174. https://doi.org/10.1017/S002211206800008X

[2] Castro Araujo, H., Ferreira Rodriguez, E. and Martins Leal, E. (2018) Numerical Analysis of the Liquid Ejection Due to the Gaseous Jet Impact through Computational Fluid Dynamics. REM International Engineering Journal, 71, 53-57. https://doi.org/10.1590/0370-44672015710079

[3] Kumagai, T. and Iguchi, M. (2001) Instability Phenomena at Bath Surface Induced by Top Lance Gas Injection. ISIJ International, 41, S52-S55. https://doi.org/10.2355/isijinternational.41.Suppl_S52

[4] Molloy, N.A. (1970) Impinging Jet Flow in a Two Phase System: The Basic Flow Pattern. Journal of the Iron and Steel Institute, 208, 943-950.

[5] Berger, R., Depardon, S., Rambaud, P. and Buchlin, J.M. (2009) Experimental Investigation of a $2 \mathrm{D}$ Impinging Jet on a Liquid Surface. WIT Transactions on Engineering Sciences, 63, 507-520. https://doi.org/10.2495/MPF090431

[6] Barron, M.A., Medina, D.Y., Hilerio, I. and Plascencia, G. (2014) Influence of the Slag Density on the Splashing Process in a Steelmaking Converter. ISRN Metallurgy, 2014, Article ID: 525706. https://doi.org/10.1155/2014/525706

[7] Barron, M.A., Hilerio, I. and Medina, D.Y. (2015) Slag Splashing in a Basic Oxygen Furnace under Different Blowing Conditions. Open Journal of Applied Sciences, 5, 819-825. https://doi.org/10.4236/ojapps.2015.512078

[8] Sato, S., Ando, M., Okada, J., Ueda, Y. and Iguchi, M. (2020) Prediction of Plunging Depth Induced by Top Lance Gas Blowing onto a Low-Melting-Point Metal Bath. ISIJ International, 60, 1675-1683. https://doi.org/10.2355/isijinternational.ISIJINT-2019-790

[9] Subagyo, B., Brooks, G.A., Coley, K.S. and Irons, G.A. (2003) Generation of Droplets in Slag-Metal Emulsions through Top Gas Blowing. ISIJ International, 43, 983-989. https://doi.org/10.2355/isijinternational.43.983

[10] Alam, M., Naser, J., Brooks, G. and Fontana, A. (2012) A Computational Fluid Dynamics Model of Shrouded Supersonic Jet Impingement on a Water Surface. ISIJ International, 52, 1026-1035. https://doi.org/10.2355/isijinternational.52.1026

[11] Sabah, S. and Brooks, G. (2015) Splash Distribution in Oxygen Steelmaking. Metallurgical and Materials Transactions B, 46B, 863-872. https://doi.org/10.1007/s11663-014-0238-1

[12] Li, M., Li, Q., Kuang, S. and Zou, Z. (2016) Determination of Cavity Dimensions Induced by Impingement of Gas Jets onto a Liquid Bath. Metallurgical and Materials Transactions $B, 47,116-126$. https://doi.org/10.1007/s11663-015-0490-z 